\title{
A normatização dos corpos e a regulação dos gêneros no processo de transição do feudalismo para o capitalismo
}

Body normalization and gender regulation in the transition from feudalism to capitalism

La normalización de los cuerpos y la regulación de los géneros en el proceso de transición del feudalismo para el capitalismo

\author{
Marcus Reis ${ }^{1 *}$ \\ ${ }^{1}$ Universidade Federal de Minas Gerais, Belo Horizonte, Minas Gerais, Brasi
}

FEDERICI, Silvia. Calibã e a bruxa. Mulheres, corpo e acumulaçáo primitiva. Trad. de Coletivo Sycorax. São Paulo: Elefante, 2017. Tomo I: Migraciones. Ciudad de México: Palabra de Clío, 2017. 194p.l

Calibã e a bruxa (FEDERICI, 2017) não é um livro que foge aos debates atuais envolvendo o movimento feminista. O fato de a tradução desta obra para o português ter sido encabeçada justamente por um "Coletivo", o Sycorax, demonstra o alcance desse trabalho para além do contexto estadunidense. A proposta de Silvia Federici é clara ainda na introdução de sua obra, afirmando seu desejo em "esboçar a história das mulheres na transição do feudalismo para o capitalismo" como modo de explicar a relação entre essa história e a exploraçáo decorrente desse processo. Por outro lado, não se desvincula dos primeiros momentos em que o feminismo se posicionou contrariamente ao status quo, ainda que a publicaçáo original seja de 2004.

Não há, ressalte-se, um apego ao anacronismo por parte de Silvia Federici, como se o conceito de gênero fosse utilizado para enxergar as raízes do feminismo na Época Moderna. A originalidade de sua obra consiste em se preocupar não apenas com a mul- tiplicidade que o conceito de mulher possui, mas principalmente com os espaços sociais distintos e atrelados ao fenômeno sobre o qual a autora se debruça. É nesse sentido que Federici parte para o uso em plural da ideia de mulher, assumindo, no âmbito de seu trabalho, o entendimento de que as práticas capitalistas são essenciais para perceber como as relaçóes sociais em que as mulheres se inseriram estiveram marcadas por um contexto de exploração (p. 27).

Há, também, a preocupação em discutir os conceitos de caráter marxista antes mesmo de operacionalizá-los, como a noçáo de acumulaçáo primitiva. Ao tratar dessa noção, a autora a articula ao objetivo central de sua obra, a "caça às bruxas", afirmando que esse fenômeno, seja no mundo europeu ou no Novo Mundo, "foi tão importante para o desenvolvimento do capitalismo quanto a colonização e a expropriação do campesinato europeu de suas terras" (p. 26). É nesse objetivo que, aliás, Federici destaca seu distanciamento das análises de Marx na medi- 
da em que o autor, a seu ver, negligenciou a participação das mulheres no contexto da acumulação primitiva. Se Marx "tivesse olhado sua história [do capitalismo] do ponto de vista das mulheres" (p. 27), não teria afirmado que o capitalismo prepararia o caminho para a libertação do proletariado. É, portanto, na tentativa de ampliar a ótica marxista ao atrelá-la à categoria de gênero que seu trabalho se insere, dividindo-se em cinco capítulos.

Seu primeiro capítulo, intitulado "O mundo precisa de uma sacudida”, parte essencialmente da discussão voltada ao surgimento dos Estados Absolutistas, iniciando o debate ainda no contexto da Baixa Idade Média, caracterizada pelas relaçóes de servidão e seus conflitos. No campo das relaçôes de gênero, a contribuição da autora reside no interesse em atrelar o surgimento desses Estados a uma forte política de regulação dos sexos, dos papéis sociais que homens e mulheres deveriam cumprir, apontando para o forte revés sofrido pelas mulheres por conta da legalização do estupro. O resultado disso, para além da degradação da honra feminina, foi o fato de que essa legalização “insensibilizou a população frente à violência contra as mulheres, preparando o terreno para a caça às bruxas que começaria nesse mesmo período" (p. 104).

"A acumulação do trabalho e a degradação das mulheres" confere título ao segundo capítulo da obra de Federici, acompanhando a lógica que finalizou o capítulo anterior, atrelando a emergência dos Estados Absolutistas à maior degradação social das mulheres e à emergência de uma nova feminilidade. É nesse espaço de discussóes que, por exem- plo, a autora retoma o conceito de acumulação primitiva. Ao defender a hipótese de que esse conceito náo diz respeito apenas a uma "acumulação e concentração de trabalhadores exploráveis e de capital", a autora o entendeu como contexto de reformulação das relaçôes de trabalho a partir da sujeição das mulheres. No entender de Federici, esse contexto contribuiu para o processo de ressignificação das funçóes sociais prescritas às mulheres, que teria atingido seu auge no século XIX “com a criação da dona de casa em tempo integral", na medida em que à figura feminina coube exclusivamente o papel de reprodutora, distanciando-a da vida pública por conta da nova divisão sexual do trabalho. ${ }^{1}$

É também nesse segundo capítulo que a autora passa a apresentar com mais clareza sua hipótese central de trabalho: o fenômeno de caça às bruxas corresponderia à maior derrota sofrida pelas mulheres na medida em que teria culminado no surgimento de um novo modelo de feminilidade. As mulheres seriam, assim, destituídas do universo público, relegadas ao papel de reprodutoras, esposas, viúvas ou prostitutas, ficando, por fim, distantes das "relaçóes coletivas e [dos] sistemas de conhecimento que haviam sido a base do poder das mulheres na Europa pré-capitalista” (p. 187). Desse modo, até finais do século XVII o que predominou foi um novo "cânone cultural", encarando as mulheres como "selvagens, mentalmente débeis, de desejos insaciáveis, rebeldes, insu-

\footnotetext{
${ }^{1}$ É nesse contexto de disciplinamento dos corpos e de normatização das mulheres, atrelando-as ao papel reprodutivo, que a autora enxerga um forte paralelo com o aumento dos processos envolvendo os delitos de infanticídio e bruxaria (p. 157).
} 
bordinadas, incapazes de se controlarem".

Seu terceiro capítulo, "O grande calibã", analisa como esse processo de disciplinamento dos corpos direcionado às mulheres foi colocado em prática ao longo da Época Moderna, já que, no capítulo anterior, a autora discutiu as bases que permitiram o avanço dessa estrutura normativa. Esse novo contexto foi caracterizado pela dicotomia da "Razão e as Paixóes do Corpo". Como pano de fundo desse binômio, enxergou a emergência de uma "engenharia social" interessada em reinterpretar as funçôes do corpo e inseri-lo numa nova lógica em que este foi encarado como fonte de todos os males. Sob a filosofia mecanicista, interessada amplamente em destrinchar as funçóes corporais, Federici percebeu como o controle da classe dominante sobre o mundo natural se deu progressivamente até culminar no "controle sobre a natureza humana”. Como consequência, ocorreu a morte do conceito de corpo enquanto receptáculo de forças mágicas, amplamente difundido ao longo do Medievo. Aqui, sentimos falta de uma reflexáo mais atenta à diversidade documental do período. Nesse sentido, em que medida essa morte de fato teria ocorrido nos séculos XVI e XVII se tomássemos por base as narrativas presentes nos processos dos diversos tribunais do Santo Ofício, e não somente os tratados da época?

Outro argumento empregado por Federici baseia-se no crescente interesse $\mathrm{da}$ burguesia em desclassificar a magia, encarando-a como principal entrave para o disciplinamento social e, por consequência, do trabalho. Esse ataque aos indivíduos que se valiam do sobrenatural como forma de resposta às demandas cotidianas, foi, inclusi- ve, um dos principais alicerces para que os Estados investissem na perseguiçáo contra a magia, resultando no fenômeno que é base do trabalho da autora. Disciplinar o corpo esteve, portanto, diretamente relacionado à desconstrução da magia, ambas tornando-se "laboratório no qual tomou forma e sentido a disciplina social” (p. 261).

Seu penúltimo capítulo, "A grande caça às bruxas na Europa", busca, em sua essência, confirmar que o fenômeno da caça às bruxas foi resultado de um processo planejado e encabeçado pelas diversas estruturas de poder, maiormente Igreja e Estados, a fim de levar adiante um disciplinamento social em que as mulheres foram subjugadas. ${ }^{2}$ Foi, portanto, "iniciativa política", ${ }^{3}$ com forte atuação da Igreja Católica por fornecer o "arcabouço metafísico e ideológico" que sustentou as perseguiçóes a partir do século XVI. Além disso, tais perseguiçóes devem ser vistas como uma reação à resistência das mulheres contra as relaçôes capitalistas que ressignificaram a feminilidade.

\footnotetext{
${ }^{2} \mathrm{Um}$ dos argumentos mais sólidos que a autora construiu referente à submissão feminina no âmbito da caça às bruxas diz respeito à mudança de status adquirida pela figura do Diabo a partir do século XVI, deixando de ser escravo e servo das mulheres, tornando-se figura abominável, "seu dono e senhor, cafetão e marido". Tanto é que o pacto diabólico, considerado pelos demonólogos como auge dos rituais empreendidos pelas mulheres com a figura do Diabo, evocava a supremacia masculina através de tal personagem, para a qual as mulheres deveriam prestar juramento (p. 338).

${ }^{3}$ A autora chega a afirmar que a "caça às bruxas foi o primeiro terreno de unidade na política dos novos Estados-nação europeus", muito por conta de protestantes e católicos terem compartilhado do mesmo interesse em coibir a presença da bruxaria entre seus fiéis (p. 303).
} 


\section{Marcus Reis}

Por fim, esse fenômeno foi instrumento de construção de uma ordem patriarcal que criou modelos de feminilidade prescritos às mulheres, tornando seu "trabalho, seus poderes sexuais e reprodutivos" a serem controlados pelos Estados, segundo a forma de força de trabalho defendida pela burguesia. Se pensarmos numa síntese do que foi esse fenômeno, segundo Federici, poderíamos dizer que a caça às bruxas foi "uma guerra contra as mulheres; [...] uma tentativa coordenada de degradá-las, demonizá-las e destruir seu poder social [...] onde se forjaram os ideais burgueses de feminilidade e domesticidade" (p. 334).

O derradeiro capítulo, "Colonização e cristianização", se debruça na extensão que o fenômeno da caça às bruxas adquiriu no Novo Mundo. A autora defende que a abrangência desse fenômeno para além do espaço europeu foi motivada pelo interesse das autoridades em utilizá-lo como ferramenta capaz de minar a "resistência anticolonial e anticapitalista" e levar adiante o interesse exploratório. Seu foco se direcionou basicamente ao contexto da América espanhola, percebendo similaridades com o processo de definição da bruxaria no âmbito europeu, como no perfil das mulheres que foram acusadas por esse delito no espaço americano: "as mulheres se converteram nas principais inimigas do domínio colonial, negando-se a ir à missa, a batizar seus filhos, ou a qualquer tipo de cooperação com as autoridades coloniais e os sacerdotes" (p. 402). Tal qual na Europa, a perseguição se direcionou ao combate de práticas e crenças heterodoxas ao catolicismo bem como às revoltas contra o sistema dominante, neste caso, colonialista.

Ao conferir protagonismo a um "sistema em que a vida está subordinada à produção de lucro" (p. 35), o que implica na imposição da violência, a autora acaba por privilegiar sua análise a partir de uma estrutura hegemônica. E, talvez, seja no excessivo olhar estruturante de sua obra que as análises empreendidas por Federici perdem força, principalmente em relação a outros campos de discussóes associados ao fenômeno estudado. ${ }^{4}$ Perde-se a avaliação precisa do peso das práticas encabeçadas pelas mulheres como resultado da própria crença dessas mulheres na sua capacidade de dialogar com o sobrenatural. Ao enxergar nas práticas heréticas protagonizadas por elas ao longo da Baixa Idade Média como exemplos claros de uma verdadeira "revoluçáo sexual", a autora cai no risco de desconsiderar que, por vezes, essas mesmas mulheres, ao ingressarem no universo do sobrenatural, almejavam apenas a manutenção de seus casamentos, sem que a estrutura normativa fosse colocada em xeque. ${ }^{5}$

Mesmo ao chamar o "Novo Mundo"

\footnotetext{
${ }^{4}$ Como, por exemplo, a possibilidade de promover estudos mais aprofundados das crenças, das práticas, da possibilidade de se compreender o universo mágico-religioso e suas relações entre os indivíduos a partir do entendimento de que havia ali uma coerência interna distanciada do materialismo.

${ }^{5}$ No contexto da Coimbra Seiscentista, José Pedro Paiva identificou a predominância das mulheres casadas como as maiores interessadas em contar com a ajuda das feiticeiras para a manutençáo de seus casamentos. Cf.: PAIVA, José Pedro. O papel dos mágicos nas estratégias do casamento e na vida conjugal na diocese de Coimbra (1650-1730). Coimbra: Faculdade de Letras da Universidade de Coimbra, 1990, p. 168-169; 180-182.
} 
para o debate, relacionando-o ao contexto de perseguição à feitiçaria, a autora não se descola de um olhar homogeneizante, como ao considerar o período de 1580 a 1630 como ápice da "caça às bruxas". Se partirmos para a América portuguesa, espaço que é negligenciado em sua obra, é possível perceber que, mesmo no século XVIII, os índices de denúncias e processos promovidos pela Inquisição portuguesa por esse delito são elevados, até maiores que os números relativos ao século XVI. ${ }^{6}$

Mesmo nesse século, as realidades são diversas quando comparamos regióes distantes, ainda que seja possível identificar algumas coerências nos argumentos da autora. No contexto inglês, Federici enxerga uma relação intrínseca entre o elevado número de acusaçôes contra supostas feiticeiras em Essex e a grande quantidade de terras cercadas nessa região. $\mathrm{O}$ mesmo vale quando a autora, concordando com Henry Kamen, estabelece um paralelo entre as graves crises econômicas e o avanço da perseguição à bruxaria, já que muitas mulheres participaram das revoltas como protagonistas. No entanto, a imprecisão existe quando outros contextos são comparados, como em Portugal, em que a realidade é outra. Conforme apontou Francisco Bethencourt, nesse espaço, a figura da mulher, pobre e marginalizada socialmente, pouco apareceu nos processos da Inquisição lusitana.?

\footnotetext{
${ }^{6}$ MATTOS, Yllan de. A última Inquisição: os meios de ação e funcionamento do Santo Ofício no Grão-Pará pombalino. 1750-1774. Jundiaí: Paco Editorial, 2012. 7 BETHENCOURT, Francisco. O imaginário da magia. Feiticeiras, adivinhos, curandeiros em Portugal no século XVI. São Paulo: Companhia das Letras, 2004, p. 371. Destaque-se ainda, entre os denunciantes, a multiplicidade de classes sociais
}

Por fim, outro importante debate historiográfico no qual se insere Calibã e a bruxa diz respeito ao entendimento da autora de que a misoginia, juntamente com o conceito de acumulação primitiva, contribuiu decisivamente para que a "caça às bruxas" se sustentasse como importante ferramenta de submissão das mulheres aos mecanismos de poder marcadamente masculinos. Trabalhos como o apresentado por Silvia Federici demarcam, assim, uma diferença visível em relação a outro viés analítico defendido, por exemplo, por Stuart Clark, no qual o peso da misoginia é relativizado.

Em Pensando com demônios, o conceito de contrariedade é tomado como base para refutar a ideia de que a misoginia foi o grande pilar que sustentou a demonologia e a "caça às bruxas". Clark parte do entendimento de que a modernidade europeia sustentou suas visóes de mundo e interpretaçôes a partir de um "extremismo cognitivo", do qual a figura da "bruxa" foi resultado direto. Bem e Mal se tornaram conceitos essenciais para tais sociedades. ${ }^{8}$ Esse novo "idioma" foi recorrente não apenas nos corredores eclesiásticos, mas também no modo como a religiosidade foi vivenciada, fazendo com que a alma do indivíduo fosse objeto de disputas. Assim, a misoginia perde força como categoria explicativa, na medida em que a contrariedade se tornou o elemento capaz de explicar os motivos das mulheres terem sido relacionadas à bruxaria. ${ }^{9}$

Por isso, ao perceber a pouca ocorrência de

interessadas em denunciar o delito da feitiçaria.

${ }^{8}$ CLARK, Stuart. Pensando com demônios. A ideia de bruxaria no princípio da Europa Moderna. Trad. de Celso Mauro Paciornik. São Paulo: Editora da Universidade de São Paulo, 2006, p. 87.

${ }^{9}$ Ibidem, p. 187. 


\section{Marcus Reis}

tratados que se interessaram exclusivamente em injuriar as mulheres e tendo em vista que os trabalhos da época pouco se direcionaram a "explorar o fundamento da bruxaria no gênero", ${ }^{10}$ o autor defendeu a necessidade de se relativizar o uso da noção de misoginia. No entanto, ao afirmar que havia uma conexão óbvia para os estudiosos entre a presença das mulheres e a sua predisposição às influências diabólicas, a ponto de fazerem com que tais autores não sentissem "a menor necessidade de elaborar sobre ela ou apelar para o ódio às mulheres em seu respaldo", Stuart Clark acabou por abrir uma aresta nos seus pressupostos, o que faz com que trabalhos como o de Silvia Federici seja um importante contraponto a esse viés.

Essa relativização por parte do autor a respeito da misoginia foi sustentada por outras duas interpretaçóes. Clark percebeu que na maioria das vezes os tratados demonológicos não se interessaram exclusivamente em injuriar as mulheres - elemento que, a seu ver, sustenta a ideia de misoginia. Além disso, os tratados interessados em discutir sobre o fenômeno da bruxaria "mostraram pouco interesse tanto em explorar o fundamento da bruxaria no gênero quanto em usá-la para denegrir as mulheres". Assim, as obras que foram amplamente difundidas pela historiografia como exemplo da misoginia presente nas perseguiçôes à bruxaria, como o Malleus Maleficarum e os tratados de Jean Bodin e Martin del Rio, foram encaradas sob uma leitura isolada que pouco ou quase nada se preocupou com a justificativa da presença de mulheres no fenômeno da bruxaria. Todavia, os argumentos de Stuart Clark também

${ }^{10}$ Ibidem, p. 166. são passiveis de críticas.

Se há uma obviedade na conexão entre a figura das mulheres e a presença do Diabo, conforme aponta o autor, ${ }^{11}$ não é na identificação desse caráter que reside a chave para a compreensão de todo o fenômeno de "caça às bruxas". Em Calibã e a bruxa, o aspecto central para responder à problemática levantada consistiu justamente em conferir peso à misoginia como instrumento que sustentou a conexão citada, sem perder de vista que a história das mulheres em meio ao contexto de "caça às bruxas" é uma história eivada de trajetórias por vezes silenciadas, inclusive pelos próprios historiadores que negligenciaram o peso das estruturas de poder na normatização dos corpos, na definição dos gêneros e na sustentação de uma heterossexualidade compulsória. Um dos méritos da obra de Federici consiste justamente em perceber como o consenso entre as autoridades religiosas e civis produziu uma série de mecanismos de vigilância e normatização interessados na manutenção do binarismo masculino/feminino. Vide exemplo apontado pela autora nos discursos que se produziram a respeito do pacto diabólico, em que, mesmo ao defenderem a existência de rituais em que as mulheres negavam o catolicismo, se relacionavam com os diabos e consolidavam sua posição de "feiticeiras", prevalecia a supremacia masculina: "as mulheres tinham

\footnotetext{
11 "Os autores sobre bruxaria evidentemente davam como certo uma maior propensão das mulheres ao demonismo, e tudo em seu ambiente cultural os encorajava a isso. A conexão era tão óbvia para eles, tão profundamente enraizada em suas crenças e comportamento, que não sentiam a menor necessidade de elaborar sobre ela ou apelar para o ódio às mulheres em seu respaldo.” Cf.: Ibidem, p. 168.
} 
que ser retratadas como subservientes a um homem [o Diabo] e o ponto culminante de sua rebelião - o famoso pacto com o diabo - devia ser representado como um contrato de casamento pervertido" (p. 343).

Calibã e a bruxa é uma obra que merece uma leitura atenta por se preocupar em compreender os longos séculos de associação das mulheres à figura do Diabo, à predisposição ao delito da feitiçaria, ou bruxaria, sem isolar as trajetórias dessas mulheres dos motivos que sustentaram essa associação. Por isso a relevância de sua obra: reafirmar a necessidade de se compreender passado e presente sem negligenciar o peso das relaçôes de gênero e dos papéis sociais atribuídos aos homens e mulheres. Além disso, se levarmos em consideração não apenas a temática em que a autora se debruça, mas também o recorte temporal escolhido, percebemos o quão necessário são as publicaçôes interessadas em articular religiosidade e relaçôes de gênero na Época Moderna, tornando-se exemplos da diversidade de interpretaçôes resultantes dessa interaçáo. Para o contexto brasileiro, que tem acesso relativamente tardio à publicaçáo em português de Calibã e a bruxa, tais aspectos estáo igualmente presentes (talvez até com maior peso). Eles nos permitem entender que o estudo da bruxaria está longe de se esgotar quando o conceito de gênero é operacionalizado.

\section{Referência bibliográfica}

FEDERICI, Silvia. Calibã e a bruxa. Mulheres, corpo e acumulaçáo primitiva. Trad. de Coletivo Sycorax. São Paulo:
Elefante, 2017. Tomo I: Migraciones. Ciudad de México: Palabra de Clío, 2017. 194p. 